mg/L (Jeziorski et al., 2008a), suggesting that the threshold measured under natural conditions may actually be higher than the $1.5 \mathrm{mg} / \mathrm{L}$ threshold identified in laboratory studies. The number of lakes at or nearing this threshold is considerable and increasing; an examination of changes in Ca concentrations for a set of 770 lakes covering a broad geographical area in Ontario (Canada) found that 35\% of lakes currently have $<1.5 \mathrm{mg} / \mathrm{L}$ of $\mathrm{Ca}$, while $62 \%$ are already below $2.0 \mathrm{mg} / \mathrm{L}$, reflecting substantial increases in percentages since the 1980s (Jeziorski et al., 2008a).

\section{Future research avenues}

We are continuing to examine the use of crustacean zooplankton as indicators of past Ca conditions across a wide spectrum of Canadian Shield lakes. For example, to better interpret changes observed in sediment profiles, more information is required regarding specific laboratorydetermined Ca thresholds for taxa other than Daphnia pulex to further refine our current separation of taxa into Ca-rich vs. Ca-poor categories. Additionally, further examinations of the potential indirect impacts of Ca decline are warranted, such as the differential uptake of $\mathrm{Ca}$ and $\mathrm{Sr}$, and/or isotopic differences as $\mathrm{Ca}$ concentrations fall (Peters et al., 2008). Finally, Ca decline has been largely attributed to either acid deposition, biomass harvesting or some combination of both, yet similar declines have been observed in regions where the effects of these stressors have been minimal, and so other environmental changes, such as decreases in atmospheric deposition of particulate dust (Hedin et al., 1994) may also be contributing to the observed Ca declines. Given our limited current understanding of both the biological consequences of reduced Ca availability, as well as its geographic extent, further investigations are clearly warranted.

\section{Note}

The term "aquatic osteoporosis" was coined by M. Turner, a co-author on Jeziorski et al., 2008a.

\section{References}

Ashforth, D. and Yan, N.D., 2008: The interactive effects of calcium concentration and temperature on the survival and reproduction of Daphnia pulex at high and low food concentrations, Limnology and Oceanography, 53: 420-432.

Cairns, A. and Yan, N., 2009: A review of the influence of low ambient calcium concentrations on freshwater daphniids, gammarids and crayfish, Environmental Reviews, 17: 67-79.

Jeziorski, A. et al., 2008a: The widespread threat of calcium decline in fresh waters, Science, 322: 1374-1377.

Likens, G.E., Driscoll, C.T. and Buso, D.C., 1996: Long-term effects of acid rain: Response and recovery of a forest ecosystem, Science, 272 $244-246$

Smol, J.P., 2008: Pollution of Lakes and Rivers: A Paleoenvironmental Perspective, Second Edition, Blackwell Publishing, Malden.

For full references please consult:

www.pages-igbp.org/products/newsletters/ref2009_3.htm

\title{
Calibration-in-time: Transforming biogeochemical lake sediment proxies into quantitative climate variables
}

Martin Grosjean, L. von Gunten, M. Trachsel and C. KameniK

Oeschger Centre for Climate Change Research and Institute of Geography, University of Bern, Switzerland; martin.grosjean@oeschger.unibe.ch

Lake sediment records are underrepresented in comprehensive quantitative high-resolution (annual, subdecadal) multi-proxy climate reconstructions for the past $1 \mathrm{ka}$ due, in part, to the problems associated with calibration of biogeochemical lake sediment proxies. Here we present a case study and highlight five methodological issues that are important to establish quantitative paleoclimate records from biogeochemical proxies in non-varved lake sediments.

Comprehensive quantitative annually resolved multi-proxy climate reconstructions for the past ca. 1 ka are arguably among the most spectacular and widely recognized highlights of current paleoclimate research (see PAGES Focus 2: Regional Climate Dynamics). In this context, lake sediment archives are surprisingly underrepresented in the data series used for such purposes. Indeed, the number of well-calibrated long time series of quantitatively reconstructed climate variables at (near) annual resolution derived from lake sediments is limited; most of the reconstructions are descriptive, and samples have variable temporal resolution or are discontinuous; with the exception of the few annually laminated lake sediments.

In contrast to biota-based transfer functions (e.g., diatoms, pollen, chironomids; e.g., Birks, 1998), bio-geochemical sediment proxies can be transformed into quantitative climate variables only through a calibration-in-time approach: a time series of sediment proxies regressed against a series of meteorological observations.
Recently, we started to explore possibilities to produce millennial-long, highly resolved (near-annual) quantitative climate reconstructions from biogeochemical data using a calibration-in-time approach in non-varved lake sediments (von Gunten et al., 2009a). The question was "can a methodology be developed to produce time series of adequate quality for regional climate reconstructions?" Yes, and the result is shown in Figure 2.

The statistical procedure per se is known from tree-ring research (e.g., Cook et al., 1994; Esper et al., 2005) and has been applied in quantitative climate reconstructions from annually laminated lake sediments (e.g., Trachsel et al., 2008). But would a calibration-in-time also work in non-varved sediments? Evidently, two things are needed: a) an extremely accurate high-resolution sediment chronology with smallest uncertainties for the calibration period (which typically covers ca. 100 years; von Gunten et al., 2009b; Fig. 1); and b) sediments corresponding to the calibration period must be sampled at highest possible resolution (e.g., near-annual; von Gunten et al., 2009a; Fig. 2). We consider the following five methodological issues to be highly critical for the success of this approach:

\section{1) Rigorous testing of calibration chronology}

While radiometric techniques (mostly ${ }^{210} \mathrm{~Pb}$ ) are widely used to date young sediments, little attention is paid to the choice and evaluation of the numerical model used to convert activity profiles into sediment ages. Although well documented (e.g., Appleby, 2008), it is often ignored that the three established models (Constant Flux Constant Sedimentation, CFCS; Constant Initial Concentration, CIC; Constant Rate of Supply, CRS) may yield very different chronologies for the same profile (Fig. 1A). A fourth model, the inductive Sediment Isotope Tomography (SIT) model is poorly established in the paleolimnological literature. SIT uses a forward modeling approach and calculates, in contrast to $\mathrm{CIC}$ and CRS, sediment ages without a-priori model assumptions (Carroll and Lerche, 2003). Our systematic comparison of all the models in two different lakes in Chile (Fig. 1; von Gunten et al., 2009b) shows 


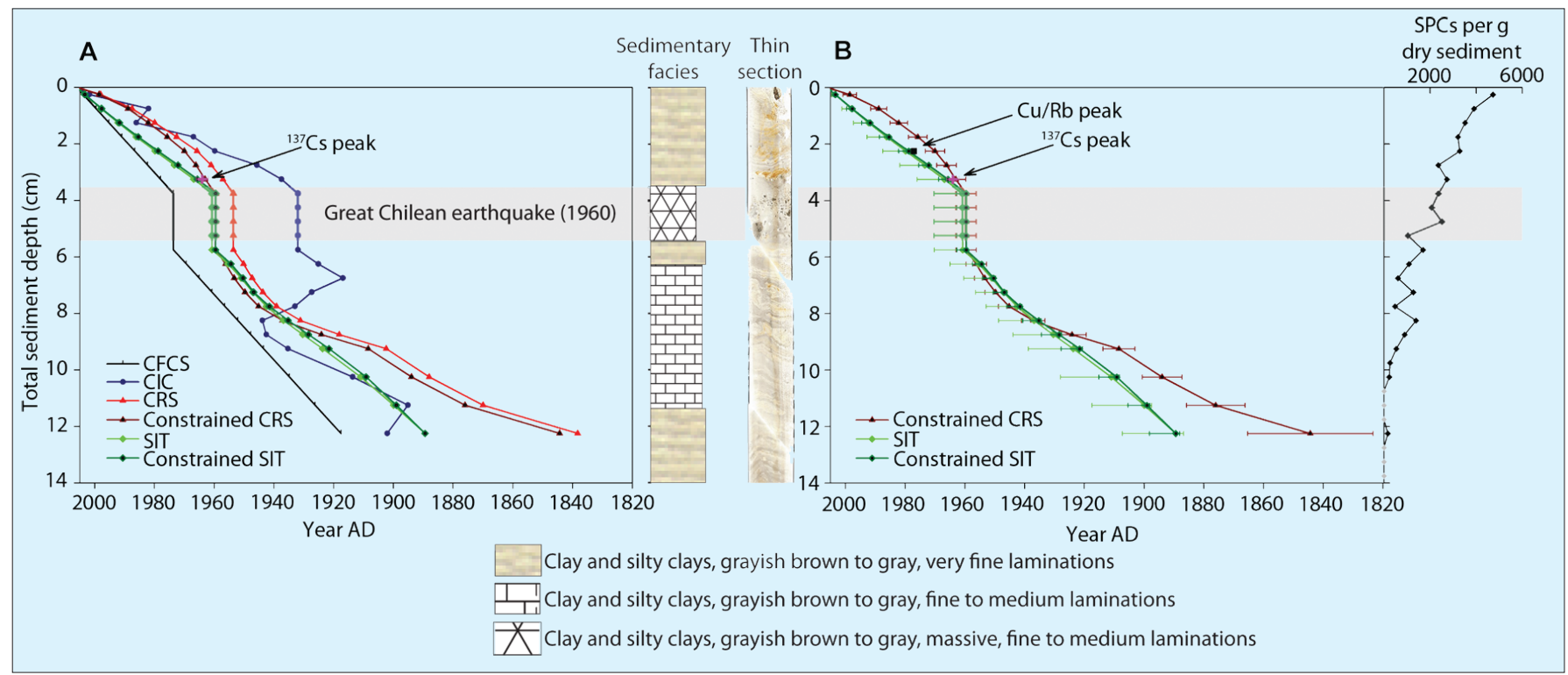

Figure 1: Calibration chronologies for Laguna El Ocho, central Chile (von Gunten et al., 2009b). A) Different results obtained for the six chronological models applied; the dating uncertainty is not shown here. The turbidite between $4-5.5 \mathrm{~cm}$ sediment depth (gray bar) is related to the 1960 earthquake. B) The two most plausible chronologies; the SIT model (green line) has been verified (CRS model falsified) with a documented (AD 1977) Cu emissions peak of a nearby Cu mine (expressed as Cu/Rb ratio), the ${ }^{137} \mathrm{Cs}$ peak $A D$ 1964, the 1960 earthquake and the Spheriodal Carbonaceous Particles (SCPS) profile for the lower part of the chronology (large smelter installed AD 1909).

that the SIT model yields the best results compared with independent chronostratigraphic markers of known age. Indeed, testing against such markers (e.g., flood markers, tephra layers, seismites, Spheroidal Carbonaceous Particle (SCP) profiles) provides an objective choice for the selection of the "best" ${ }^{210} \mathrm{~Pb}$ chronology (and rejection of the others).

\section{Conclusion 1:}

We recommend routine calculation and comparison of chronologies from all three standard models (CIC, CRS and SIT), tests of robustness and verification against independent markers (available in most cases) to identify the best chronology.

\section{2) Reducing uncertainty in the chronology}

All sediment ages are probabilistic. Typically, the standard deviation increases with increasing depth or age. It is the standard deviation of the chronology during the calibration period (i.e., last 100 years) that is critically important for calibration-intime. The time series of proxy data needs to be smoothed to account for dating uncertainties before a regression with meteorological data is possible (Koinig et al., 2002). Consequently, the standard deviation in the chronology determines the degree of smoothing needed and, finally, the maximum possible resolution of the climate reconstruction (or the loss of the high-frequency component of climate variability). The software of the SIT model (Carroll and Lerche, 2003) allows the numerical assimilation of ${ }^{210} \mathrm{~Pb}$-independent discrete chronostratigraphic markers (forcing the forward modeling through a specific age/depth point), while reducing the standard error of the continuous model chronology. This is of significant advantage for calibration-in-time, in particular for the early instrumental period when dating errors are typically high.

\section{Conclusion 2:}

Independent stratigraphic markers are worth the extra effort and are important to reduce the standard deviation of the chronology in the calibration period. This has direct consequences for the quality of the calibration and for the maximum temporal resolution of the reconstruction and, ultimately, for the preservation of the high-frequency signal in the paleoclimate variability.

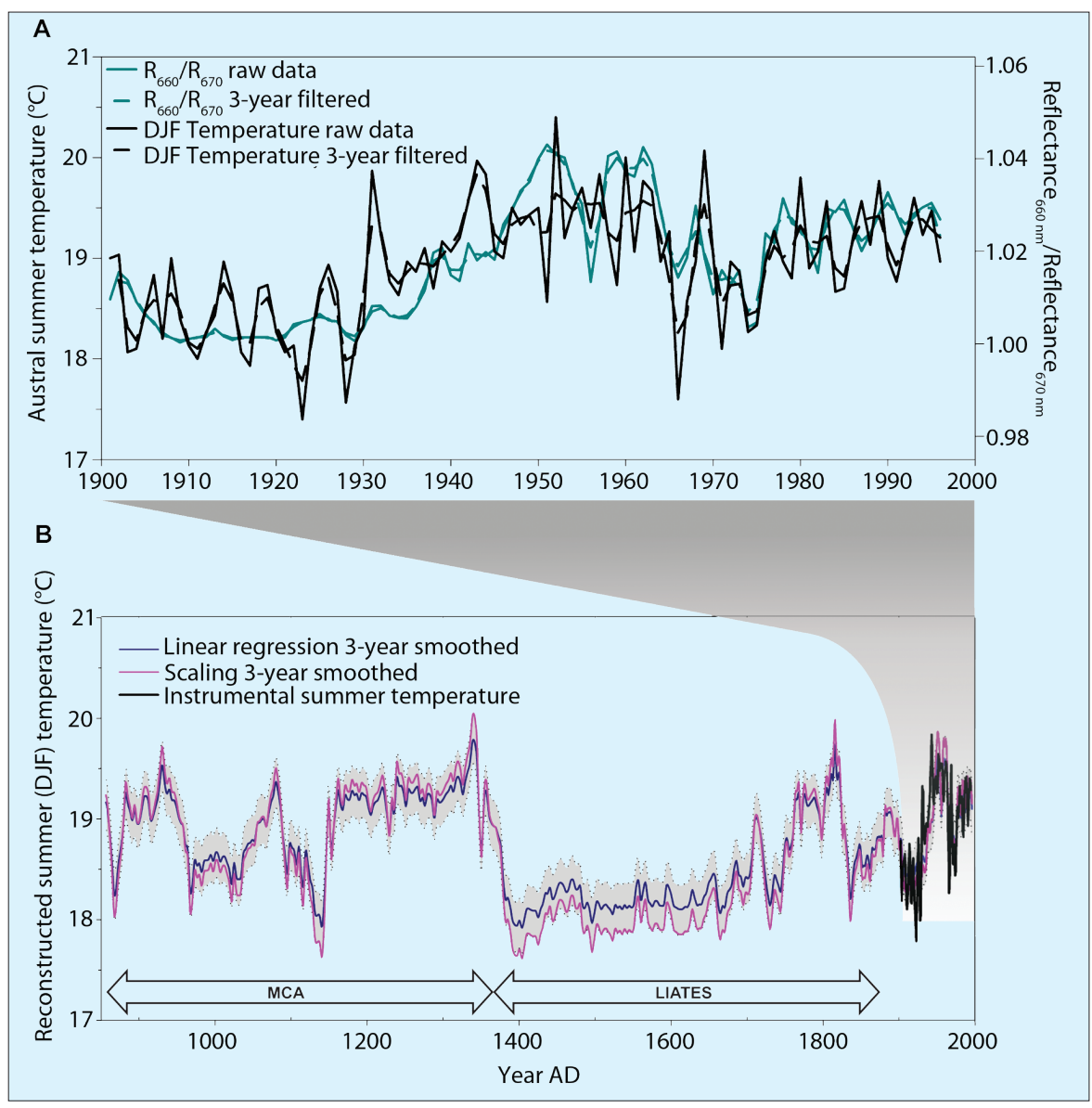

Figure 2: A) Calibration-in-time and calibration statistics for raw data and 3-year filtered data of Laguna Aculeo, central Chile; we used the reflectance ratio $R 660 \mathrm{~nm} / \mathrm{R} 670 \mathrm{~nm}$ (non-destructive in-situ high-resolution reflectance spectroscopy) as a proxy for austral summer temperature. Loss of the inter-annual climate variability in the sediments (blue line compared with black line) is likely due to bioturbation. B) Instrumental DJF temperatures and the reconstruction back to AD 850 (3-year resolution). MCA = Medieval Climate Anomoly, LIATES = Little Ice Age Type Events. Here we used the ratio Reflectance $660 \mathrm{~nm} /$ Reflectance $670 \mathrm{~nm}$ as a proxy for the photopigments chlorin, which is significantly correlated $(p<0.01$ ) with austral summer temperature. For details seevon Gunten et al, $2009 a$. 
3) The significance of sampling, sampling resolution

This issue has two aspects: a) sediments are sampled to establish the $\left({ }^{210} \mathrm{~Pb}\right)$ chronology. Stratigraphic sampling according to sedimentary microfacies substantially improves the quality of ${ }^{210} \mathrm{~Pb}$ chronologies (Arnaud et al., 2002). Layers with rapid sedimentation (e.g., turbidites) need to be excluded; and b) samples for the analysis of the lake sediment proxies must be taken continuously and, ideally, at annual resolution, at least throughout the calibration period. This is the basic requirement to target e.g., sub-decadal climate variability (such as ENSO cycles).

Therefore, the sediment core that is used to establish the proxy data must not be cut before the chronology for the calibration period is fully established, and sampling intervals along the sediment core should be adjusted according to local sedimentation rates. Furthermore, the core used to establish the chronology and the one used to produce the proxy data series must have a perfect micro-stratigraphic match at the millimeter-scale. In practice, this is only possible on two halves of one split core, or on varved sediments. In this context, the advantage of using non-destructive methods (XRF scanning or in-situ reflectance spectroscopy scanning (Kalugin et al., 2007; Rein and Sirocko, 2002; von Gunten et al., 2009a; Fig. 2)) is obvious.

Conclusion 3:

Establish the chronology of the calibration period first, and sample the sediments for the proxy analyses afterwards (according to the chronology).

4) Sampling resolution, analysis of the meteorological data

Ultra fine "technical" sampling resolution does not necessarily correspond to the "true" resolution of (climate) variability recorded in the sediments. For a number of reasons (dating and sampling errors, synchronizing of proxy data points to a calendar scale with homogenous temporal resolution) raw proxy series must be filtered. As a rule of thumb, the resolution of the raw data series should be 3-4 times higher than the final resolution (highest frequency band of climate variability) envisaged. System-inherent filters, such as bioturbation may destroy the highest true (or meaningful) temporal resolution of climate variability that is potentially recorded in a lake. Thus, this type of research should actually start with the statistical analysis of the local meteorological time series, and calculate the sampling resolution that is required to detect the dominant features of variability, trends and extremes of the local climate.

\section{Conclusion 4:}

The "technical" and the "true" sampling resolution, and the "envisaged" (best possible) temporal resolution of the climate reconstruction have their restrictions. These must be carefully assessed.

\section{5) The properties of the calibration period}

Obviously, all the caveats for regressionbased reconstructions also apply to a calibration-in-time (e.g., non-modern analogues, long-term trends). Furthermore, the length of the instrumental meteorological time series is often limited. Moreover, many of the calibration parameters (starting and ending point, data homogenization, selection of the split periods for cross validation, etc.) are an optimization process and an expert choice. Instead of using split periods, it might be justified to use the entire meteorological data series for a proper calibration. In addition, the use of reanalysis data sets should be considered and tested (e.g., ICOADS http:// www.cdc.noaa.gov/data/ or ACRE http:// www.met-acre.org/) in areas where instrumental series are very short. Shorter calibration periods often exhibit pronounced (warming) trends, which is a problem for the calibration statistics.

Conclusion 5:

The choice of the appropriate calibration (period and parameters) is not a priori known. A novel approach would be to produce probabilistic reconstructions based on an ensemble of different calibrations.

\section{Conclusions and outlook}

New developments in scanning techniques have boosted the acquisition of high-resolution biogeochemical proxies from lake sediments. Faced with the challenges mentioned above, these data must be converted into quantitative climate (environmental) variables using calibration-in-time. We have shown here that this task can be accomplished; yet, it requires careful consideration and planning of the practical work, further refining of the methodology (as proposed above), as well as systematic exploration of the potentials and limits of the individual methods used.

\section{References}

Appleby, P.G., 2008: Three decades of dating recent sediments by fallout radionuclides: a review, Holocene, 18: 83-93.

Carroll, J. and Lerche, I., 2003: Sedimentary processes: quantification using radionuclides, Elsevier, Oxford

Trachsel, M., Eggenberger, U., Grosjean, M., Blass, A. and Sturm, M. 2008: Mineralogy-based quantitative precipitation and temperature reconstructions from annually laminated lake sediments (Swiss Alps) since AD 1580, Geophysical Research Letters, 35(13): L13707.

von Gunten, L., Grosjean, M., Rein, B., Urrutia, R. and Appleby, P., 2009a: A quantitative high-resolution summer temperature reconstruction based on sedimentary pigments from Laguna Aculeo, central Chile, back to AD 850, The Holocene, 19(6): 873-881.

von Gunten, L., Grosjean, M., Beer, J., Grob, P., Morales, A. and Urrutia, R., 2009b: Age modeling of young non-varved lake sediments: methods and limits. Examples from two lakes in Central Chile, Journal of Paleolimnology, D0l 10.1007/s10933-008-9284-5.

\title{
Environmental and climatic changes inferred from lake deposits in China: A review of recent progress
}

\author{
Patrick Rioual and Luo Wang \\ Key Laboratory of Cenozoic Geology and Environment, Institute of Geology and Geophysics, Chinese Academy of Sciences, Beijing, China; \\ prioual@mail.igcas.ac.cn
}

\section{In recent years, Chinese paleoscience including paleolimnology has made huge progress, providing a wealth of data on past environmental and climatic change on various timescales. A brief review is presented here on recent research based on Chinese lake sediment records and their significance in the PAGES context.}

\section{Climate records in the arid areas of northwestern China}

A large share of paleolimnological research in China has focused on climate records from lakes located in the vast arid and semi-arid areas of northern and west- ern China, which include the regions of Inner Mongolia, Xinjiang, Qinghai and Tibet. These climate records are concerned with changes in precipitation or effective moisture. Most of these lakes are brackish or saline and often very shallow (Fig.
1A). The most commonly used proxies are pollen, stables isotopes $\left(\delta^{13} \mathrm{C}, \delta^{18} \mathrm{O}\right)$, ostracods, grain size and various geochemical variables. Because of bad preservation in these saline, highly alkaline and shallow lakes, biological proxies, such as diatoms, 


\section{Full Reference List:}

Appleby, P.G., 2008: Three decades of dating recent sediments by fallout radionuclides: a review, Holocene, 18: 83-93.

Arnaud, F., Lignier, V., Revel, M., Desmet, M., Beck. C, Pourchet, M., Charlet, F., Trentesaux, A. and Tribovillard, N., 2002: Flood and earthquake disturbance of Pb-210 geochronology (Lake Anterne, NW Alps), Terra Nova, 14: 225-232.

Birks, H.J.B., 1998: Numerical tools in paleolimnology - Progress, potentials, and problems, Journal of Paleomimnology, 20: 307-332.

Carroll, J. and Lerche, I., 2003: Sedimentary processes: quantification using radionuclides, Elsevier, Oxford.

Cook, E.R., Briffa, K.R. and Jones, P.D., 1994: Spatial regression methods in dendroclimatology: A review and comparison of two techniques, International Journal of Climatology, 14: 379-402.

Esper, J., Frank, D.C., Wilson, R.J.S. and Briffa, K.R., 2005: Effect of scaling and regression on reconstructed temperature amplitude for the past millennium, Geophysical Research Letters, 32.

Kalugin, I., Daryin, A., Smolyaninova, L., Andreev, A., Diekmann, B. and Khlystov, O., 2007: 800-yrlong records of annual air temperature and precipitation over southern Siberia inferred from Teletskoye Lake sediments, Quaternary Research, 67/3: 400-410.

Koinig, K.A. and 11 co-authors, 2002: Environmental changes in an alpine lake Gossenkollesee, Austria) over the last two centuries-the influence of air temperature on biological parameters, Journal of Paleolimnology, 28: 147-160.

Rein, B. and Sirocko, F., 2002: In-situ reflectance spectroscopy - analysing techniques for highresolution pigment logging in sediment cores, International Journal of Earth Sciences, 91: 950954.

Trachsel, M., Eggenberger, U., Grosjean, M., Blass, A. and Sturm, M., 2008: Mineralogy-based quantitative precipitation and temperature reconstructions from annually laminated lake sediments (Swiss Alps) since AD 1580, Geophysical Research Letters, 35(13): L13707.

von Gunten, L., Grosjean, M., Beer, J., Grob, P., Morales, A. and Urrutia, R., 2009a: Age modeling of young non-varved lake sediments: methods and limits. Examples from two lakes in Central Chile, Journal of Paleolimnology, DOI 10.1007/s10933-008-9284-5.

von Gunten, L., Grosjean, M., Rein, B., Urrutia, R. and Appleby, P., 2009: A quantitative highresolution summer temperature reconstruction based on sedimentary pigments from Laguna Aculeo, central Chile, back to AD 850, The Holocene, 19/6: 873-881. 